\title{
OS PROTOCOLOS DE LEITURA COMO SUPORTE TEÓRICO- METODOLÓGICO PARA ANÁLISE NA HISTÓRIA DA EDUCAÇÃo
}

Elizabeth Figueiredo de Sá ${ }^{1}$ Dálete Cristiane Silva Heitor de Albuquerque ${ }^{2}$ (iD Sara EvelinUrreaQuintero ${ }^{3}$

\begin{abstract}
Resumo
O presente artigo pretende perceber como os protocolos de leitura, instituídos por Chartier (2001), podem auxiliar a análise de escritos voltados para a área da educação (institucional ou não). Os suportes escolhidos para análise foram: o periódico feminino Jornal das Moças e o manual escolar da Escuela Nueva na Colômbia. O referencial teórico sustenta-se nas categorias de análise, protocolos de leitura e representações, propostos por Roger Chartier. Os resultados demonstram que a utilização dos protocolos de leitura como ferramentas metodológicas da História da Leitura constroem pontes para a escrita da História da Educação, ampliando a perspectiva não só sobre a utilização de diversas fontes, mas também sobre novas perguntas e metodologias neste campo.
\end{abstract}

Palavras-chave: Protocolos de leitura; Manual escolar; Revista feminina, Representações sociais.História da Educação

\section{LOS PROTOCOLOS DE LECTURA COMO SOPORTE TEÓRICO- METODOLÓGICO PARA EL ANÁLISIS EN LA HISTORIA DE LA EDUCACIÓN}

\author{
Resumen
}

\footnotetext{
${ }^{1}$ Doutora em Educação pela Universidade de São Paulo. Pós-doutoramento em Educação na FEUSP e em andamento na Universidade Federal de Uberlândia. Docente do Programa em Pós-graduação em Educação da UFMT e coordenadora do grupo de pesquisa História da Educação e Memoria - GEM. E-mail: elizabethfsa1@gmail.com

${ }^{2}$ Mestre em Educação pelo Programa de Pós-graduação em Educação da Universidade Federal de Mato Grosso. Servidora do Instituto Federal de Educação, Ciência e Tecnologia de Mato Grosso, Reitoria - IFMT. E-mail: dalete.albuquerque@ifmt.edu.br

${ }^{3}$ Mestre em Educação pelo Programa de Pós-graduação em Educação da Universidade Federal de Mato Grosso. Professora da Universidad Católica de Oriente e Universidad de San Buenaventura. E-mail: saraurrea0718@gmail.com
} 
El presente artículo pretende percibir como los protocolos de lectura instituidos por Chartier (2001), pueden auxiliar el análisis de escritos volcados para la educación (institucional o no). Los soportes escogidos para el análisis fueron: El periódico femenino Jornal das Moças y el manual escolar de la Escuela Nueva en Colombia. El referencial teórico se sustenta en las categorías de análisis, protocolos de lectura y representaciones de Roger Chartier. Los resultados demuestran que la utilización de los protocolos de lectura como herramientas metodológicas de la Historia de la Lectura construyen puentes para la escritura de la Historia de la Educación, ampliando la perspectiva no solo sobre la utilización de diversas fuentes, sino, también, sobre nuevas preguntas y metodologías en este campo.

Palabras clave: Protocolos de lectura; Manual escolar; Revista femenina; Representaciones sociales; Historia de la educación

\title{
THE READING PROTOCOLS AS THEORETICAL- METHODOLOGICAL SUPPORT FOR ANALYSIS IN THE HISTORY OF EDUCATION
}

\begin{abstract}
The objective of this work is to give visibility to reading protocols, such as the methodological framework for the analysis of representations and texts, for investigations on the field of History of Education. The periodicals for the analysis were: the women's journal Jornal das Moças and the Escola Nueva textbook. The theoretical framework is based on Roger Chartier's categories of analysis, reading protocols and representations. The results demonstrate that the use of reading protocols as methodological tools of Reading History builds bridges to the writing of the History of Education, expanding a perspective not on a source from several sources, but also on new questions and methodologies in this field.
\end{abstract}

Keywords: Reading protocols; School manual; Women's magazine, Social Representations. History of Education

\section{INTRODUÇÃO}


Ler é sonhar pela mão de outrem. Ler mal e por alto é libertarmonos da mão que nos conduz. A superficialidade na erudição é o melhor modo de ler bem e ser profundo.

Fernando Pessoa

Fernando Pessoa em sua obra Livro do desassossego possibilita-nos refletir sobre dois aspectos da leitura: primeiramente sobre o domínio do escritor sobre a escrita ao dizer que ler é sonhar pela mão de outrem e, em contraponto, ressalta a ressignificação da escrita pelo leitor, quando este se liberta da mão que o conduz.

Ler este poema leva-nos a inquirir sobre: o que é a Leitura? Chartier (2002, p. 123), cujos estudos dão sustentação teórica a este artigo, afirma que "A leitura é uma prática criadora, atividade produtora de sentidos singulares, de significações, de modo nenhum redutíveis às intenções dos autores de textos ou dos fazedores de livros". Desse modo, a prática da leitura reconhece um leitor que dota de sentido o que lê, através das características que lhe concedem um lugar e um momento determinados, uma cultura e uma particular forma de vida, estabelecendo uma relação de apropriações diversas com o suporte de leitura. Vale a pena observar que no encontro entre o sujeito leitor e o objeto lido ocorrem diversas interferências entre um e outro, estabelecendo, assim, um cenário de maneiras diferentes de leitura, mas também limites de interpretação possível, como afirma Chartier (2001).

Do lado do sujeito, características da ordem de capacidades e habilidades leitoras, literatura percorrida, nível de escolaridade, instrumentos diferentes para apropriar-se do objeto, horizontes de expectativa e características particulares no nível social e cultural configuram um determinado leitor que não responde às idealizações inscritas no suporte de leitura. Porém, elas estabelecem limites da sua possível recepção, ou seja, dispositivos de controle. Esses dispositivos apresentam-se, também, como prescrições de uso que se conjugam com formas materiais e conteúdos explícitos e implícitos, aos que Chartier (2001) denomina como protocolos de leitura, os quais estabelecem uma leitura autorizada e estratégias que pretendem regular a mesma leitura.

Os protocolos de leitura encontram-se estabelecidos a partir de duas vias: uma puramente textual, que inscreve no texto "as convenções, sociais ou literárias, que permitirão a sua sinalização, classificação, e compreensão, empregando toda uma panóplia de técnicas, narrativas ou poéticas, que, como uma maquinaria, deverão, produzir efeitos obrigatórios, 
garantindo uma boa leitura" (CHARTIER, 2001, p. 97); +e uma segunda via que são as formas tipográficas.

Nesse sentido, o presente artigo pretende perceber como os protocolos de leitura instituídos por Chartier, podem auxiliar a análise de escritos voltados para a educação (institucional ou não). Para tal, serão utilizados a revista Jornal das Moças e os manuais escolares da Escuela Nueva, observando seus conteúdos, títulos, leituras sugeridas, nível de complexidade, anúncios publicitários, imagens que representam formas culturais e sociais válidas sobre determinadas instituições, ações e sujeitos e, sobretudo, a forma na qual se estrutura o texto, pois existem formas discursivas implícitas que fazem "do texto uma maquinaria que, necessariamente, deve impor uma justa compreensão" (CHARTIER, 2002, p. 124).

É possível afirmar que há um olhar, há uma intencionalidade nos textos produzidos e que esses estão regidos em moldes de organização bastante específicos. Porém, apesar das marcadas diferenças de público, de características, de culturas, bem como de especificidades metodológicas para a pesquisa, tomou-se como aspecto comum, que permite pesquisá-los, utilizando-se um mesmo quadro metodológico, o fato de serem suportes de leitura. $\mathrm{O}$ resultado apresentado resulta de pesquisas realizadas na pós-graduação em Educação, mais especificamente no campo da História da Educação. O objetivo, então, do presente trabalho é dar visibilidade a utilização dos protocolos de leitura como quadro metodológico na busca das representações inscritas nos textos, no viés da História da Leitura, para subsidiar as investigações no campo da História da Educação.

Inicialmente a análise se debruçará sobre o Jornal das Moças buscando perceber as representações de mulher através de suas páginas, materializadas nos artigos, propagandas, imagens e outras formas textuais. Em seguida, serão analisados os manuais de aprendizagem das Escuelas Nuevas ${ }^{4}$ colombianas, um programa do Ministério de Educação da Colômbia pensado para a formação da criança camponesa, procurando perceber as representações da ruralidade inscritas nesses manuais.

\section{REPRESENTAÇÕES DA EDUCAÇÃO DA MULHER PRESENTES NO SEMANÁRIO JORNAL DAS MOÇAS: A PRESENÇA DOS PROTOLOS DE LEITURA}

\footnotetext{
${ }^{4}$ Modelo escolar implantado nos anos 70 que se expande nas duas últimas décadas do século XX por todo o território rural colombiano, configurando-se na estratégia mais utilizada nas escolas camponesas do país.
} 
Segundo Pinsky (2012, p. 352) “a mulher é assunto". Todos falam sobre ela e para ela. $\mathrm{Na}$ imprensa feminina os periódicos organizados, para além de entreter, veiculam representações, com o intuito de ditar regras e impor costumes para a preservação de valores e padrões sociais dominantes da época. Nesse sentido, essa pesquisa procurou entender o perfil da mulher ideal a ser educada através do semanário carioca, a revista Jornal das Moças, utilizando como referencial teórico o conceito de representações em associação a um quadro metodológico de análise dos protocolos de leitura, procedendo a investigação a partir da categorização dos temas que apareciam com frequência nas páginas da revista.

A revista Jornal das Moças foi uma revista carioca que entrou em circulação no ano de 1914 e circulou até o ano de 1965, sempre às quintas-feiras, nas capitais e em algumas cidades do interior do Brasil. A análise centrou-se nos exemplares que circularam na Era Vargas, de 1930 a 1945, quando as mulheres eram cada vez mais vistas circulando pelos espaços públicos reivindicando o direito ao voto, à educação e de oportunidades de emprego, transformando, assim, os ideais de recato que vinham sendo construídos ao longo dos séculos.

A edição da revista era feita pela Empreza Jornal das Moças - Menezes, Filho \& C. Ltda e dirigida por Álvaro Menezes e Agostinho Menezes. Nela encontravam-se colunas com assuntos sobre decoração do lar, receitas culinárias, noções de higiene, dicas de conquista afetiva, felicidade conjugal, manutenção do casamento, além de fotos da alta sociedade carioca e notícias com atores e atrizes hollywoodianos que serviam para construção de modelos, de mitos de época.

A revista Jornal das Moças era um semanário ilustrado que propagava o estereótipo de "mulher ideal". Se encaixava no modelo de revista feminina centrada na fórmula consagrada de amiga-conselheira, confidentes entre si e com predominância do suposto universo feminino, como o lar e questões do coração (LUCA, 2012). Tinha como objetivo:

[...] Levar ao lar das familias patricias, além da graça e do bom humor que empolgam, da música e canto que embalam, dos brincos e contos infantis que deleitam, da moda que agrada, do romance que desfaz as visões tristes da existência, da nota mundana que satisfaz a curiosidade insofrida, os conhecimentos uteis que instruem [...] (JORNAL DAS MOÇAS, 21 de maio de 1914, n. $\left.1^{5}\right)$.

\footnotetext{
${ }^{5}$ Nesse período a revista não era paginada regularmente.
} 
Pretendia cativar suas "patrícias", elevando seus espíritos de "mulheres encantadoras", termo bastante usado para caracterizar a mulher prestimosa, cujo comportamento é calcado nos mais altos valores morais, levando-a, conduzindo-a a seguir irretocavelmente em seu caminho, além de encantadora, impoluta.

"A revista que o senhor e a senhora pode deixar em sua casa porque não há perigo de perversão em nenhuma de suas páginas" (JORNAL DAS MOÇAS, 30 abril de $1953^{6}$, p. 61), cujo subtítulo persuasivo, "a revista de maior penetração no lar", denota, não ser a mulher seu único alvo como leitora, mas também, o homem, marido, a família como um todo, mesmo voltada unicamente para assuntos femininos.

O periódico propunha espaço com colunas acerca dos direitos da mulher, sobretudo os políticos. No entanto, alguns artigos defendiam uma educação feminina que não contrapunha aos interesses da família de estar à frente do homem ou em posição de igualdade. Essa educação deveria ser voltada para uma formação compatível com a função de dona de casa, de mãe responsável pela condução espiritual dos membros do lar e a manutenção das gerações vindouras. A esse respeito, a revista aponta que a mulher deve:

Ser um pouco instruída. Conhecer bem, pelo menos, os rudimentos de aritmética e de leitura. A mulher é o primeiro funcionário do Estado Familiar, pois tem a seu cargo a importante função da despesa, de cuja anarquia rebentam tantas revoluções (JORNAL DAS MOÇAS, 1 de junho de 1914, nº 02, p. 18).

A mulher deve receber uma educação mais completa do que a comum, porque nem todas nasceram para usar o anel esponsálico nem trajar a bata da maternidade (JORNAL DAS MOÇAS, 1 de março de 1916, nº 44, p. 24).

Para tanto, há que se questionar as representações do Estado em relação à mulher, ao seu papel social e a sua educação. Gustavo de Capanema, Ministro da Educação no governo Vargas, em conferência proferida por ocasião do centenário do Colégio Pedro II, em dezembro de 1937, afirma que "a família constituída pelo casamento indissolúvel é a base de nossa organização social e por isto colcoada sob a proteção especial do Estado"7. Então, há que se delinear as preocupações que o Estado tinha para com ela. E como se configurava

\footnotetext{
${ }^{6}$ É possível encontrar em seu miolo em repetidas páginas, essas frases de confiabilidade na consulta ao periódico. Apesar do recorte temporal se restringir a Era Vargas, de 1930 a 1945, esta pesquisadora percorreu por diversos números que antecediam e sucediam esse período, por tratar de conhecer a fonte como um todo. Também, essas frases demonstravam que, apesar do passar dos anos e com o que era moderno se instalando, a revista de mantinha intacta e preocupada em trazer as suas leitoras, assuntos que não a conduzissem à comportamentos inapropriados para a época.

${ }^{7}$ Gustavo Capanema. Conferência proferida por ocasião do centenário do Colégio Pedro II, 2 de dezembro de 1937. GC/ Capanema, Gustavo, 02.12.37, série pi.
} 
essa mulher? Como seria tratada? “[...] Ora, é a mulher que funda e conserva a família, como é também por suas mãos que a família se destrói. Ao Estado, pois, compete, na educação que lhe ministra prepará-la conscientemente para esta grave missão". (SCHARTZMAN; BOMENY; COSTA, 1984, p. 107).

Percebe-se que havia de se ter um cuidado, um tratamento especial a essa formação para a mulher. Havia uma diferença no projeto de educação aos homens e às mulheres, sendo que o objetivo era prepará-los para a vida moral, política e econômica da nação, mas que haveria de se considerar as especificidades de cada um, aos "destinos que a Providência lhes deu" (SCHARTZMAN; BOMENY; COSTA, 1984, p. 107). Então, se para o homem era forjada uma educação voltada para a militância, para a vida pública, para os negócios, à mulher era destinada uma educação voltada para o seu papel no lar, da mãe que prepararia seus filhos dentro dos mesmos moldes que fora educada. Segundo Schartzman, Bomeny e Costa (1984), Capanema reservaria dois planos às mulheres, sendo um de proteção à família e outro de proporcionar uma educação apropriada ao seu papel familiar.

Para analisar a revista por meios dos protocolos de leitura, privilegiou-se sua estrutura visual entendendo que "a imagem, no frontispício ou na página do título, na orla do texto ou na sua última página, classifica o texto, sugere uma leitura, constrói um significado. Ela é protocolo de leitura, indício identificador" (CHARTIER, 1990, p. 133).

A revista Jornal das Moças se constitui como um grande catálogo de vendas de produtos das mais diferentes origens e para as mais diversas finalidades e, voltar o olhar para as propagandas ali apresentadas permite-nos vislumbrar que os produtos oferecidos traduzem as representações de padrões estéticos, delimitam seu espaço de circulação, definem sua postura, comportamento, e, determinam até o modo de se vestir.

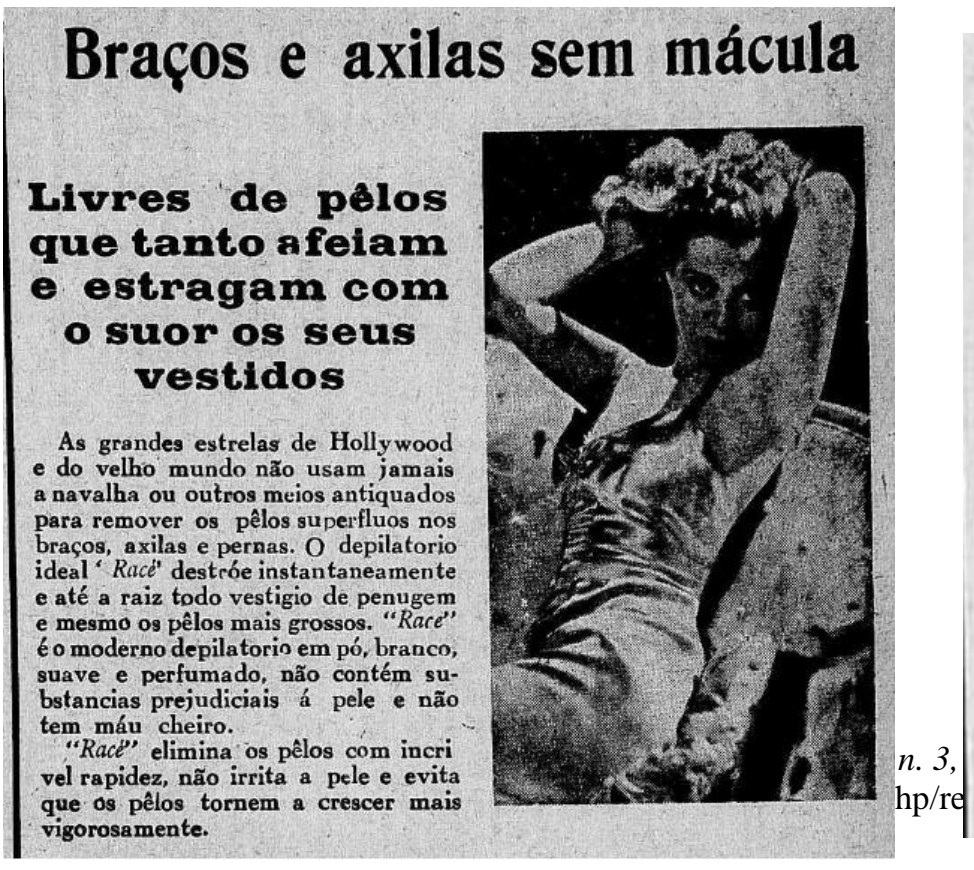

As grandes estrelas de Hollywood e do velho mundo não usam jamais a navalha ou outros meios antiquados para remover os pêlos superfluos nos braços, axilas e pernas. 0 depilatorio ideal 'Race' destée instantaneamente e até a raiz todo vestigio de penugem e mesmo os pêlos mais grossos. "Race" é o moderno depilatorio em pó, branco, suave e perfumado, não contém substancias prejudiciais á pele e não tem máu cheiro.

"Race" elimina os pêlos com incrivel rapidez, não irrita a pele e evita que os pêlos tornem a crescer mais vigorosamente. 
da foto

Observando a figura 1, a partir das discussões sobre a propriedade dos corpos, especialmente do corpo feminino, percebe-se que a revista apresenta como referência as grandes estrelas de Hollywood como ideal de mulher moderna. Mitos de feminilidade, de jovialidade, daquilo a ser copiado e desejado e que constituíam o imaginário feminino e colaboravam para sedimentar as representações de mulher veiculadas na imprensa da época, com o intuito de amadurecer e certificar o que poderia ser considerado o primeiro funcionário e elo forte no governo Vargas, a mulher. Essa mulher que seria aquela que cuidaria dos filhos da nação. Mulheres para o lar e cuidadora dos homens, que dominariam o cenário externo aos limites domésticos, que trabalhariam fora de casa, que estariam na política, que determinavam regras, escreviam leis e estabeleciam e continuavam querendo vigorar com a lógica patriarcalista existente.

Para o destino que era criada e formada, a mulher era educada para ser encantadora. Palavra de ordem na educação feminina e termo bastante comum no material publicitário que circulava no período, como pode ser visto na figura 2.

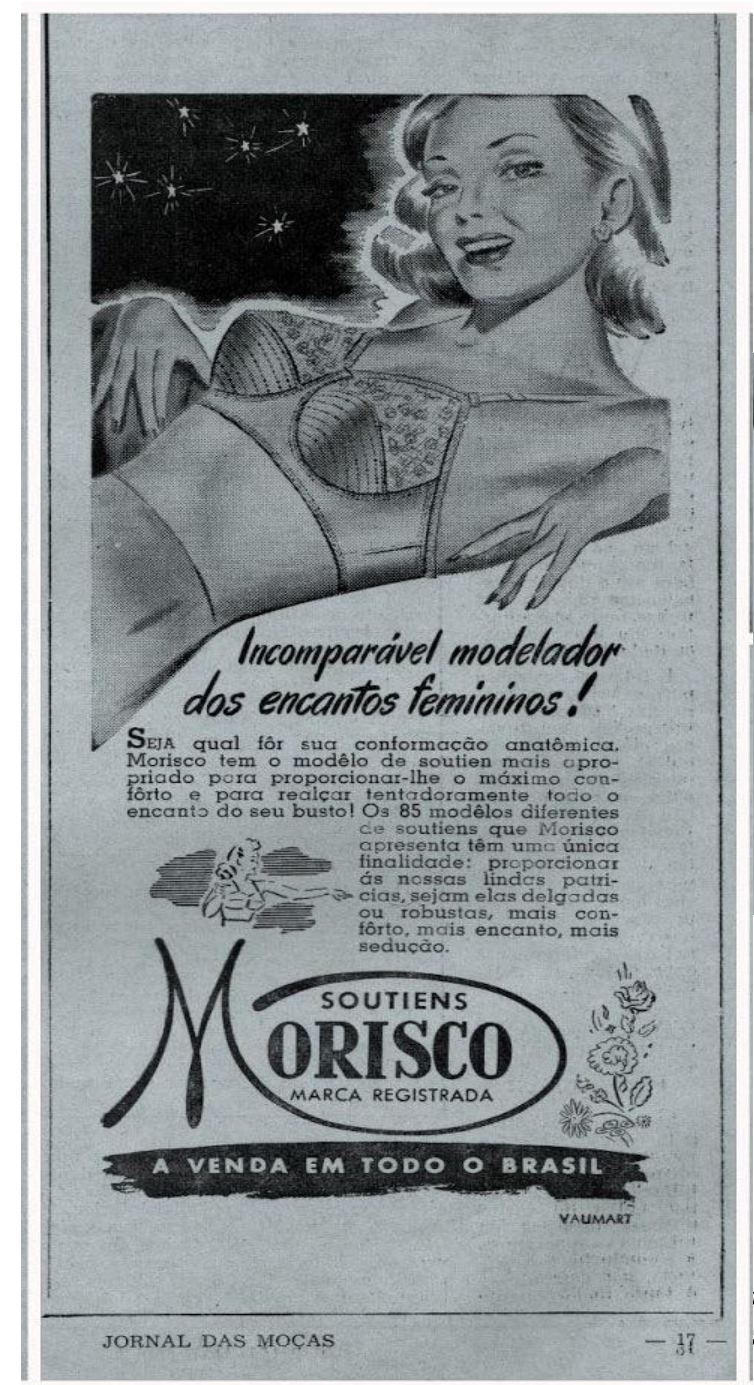

SEIA qual fôr sua conformaçào anatômica. Morisco tem o modêlo de soutien mais opropriado pora proporcionar-lhe o máximo confôrto e para realçar tentadoramente todo 0 encanto do seu busto! Os 85 modêlos diferentes de soutiens que Morisco
cpresenta têm umc única $\Rightarrow z^{3}=$ tinalidade: proporcionar ás nossas lindas patri- $a$ cias, sejam elas delgadas ou robustas, mais contôrto, mais encanto, mais seduçào. 
“Incomparável modelador dos encantos femininos!”, aqui se revela a mulher, como reprodutora, aquela que era concebida para conceber filhos e, por isso, não poderia descuidar dos desejos masculinos. O corpo da mulher como fonte de prazer e, para além disso, onde residiam os seus encantos. Ainda, em contraposição a isso a "venda" da ideia de que os incômodos femininos, trazidos pela menstruação, deixavam a mulher nervosa, suscetível a ataques nervosos, com falta de ânimo e a impertinência feminina que insistia em ser amplamente divulgada nos impressos femininos, como se encontra na Figura 3.

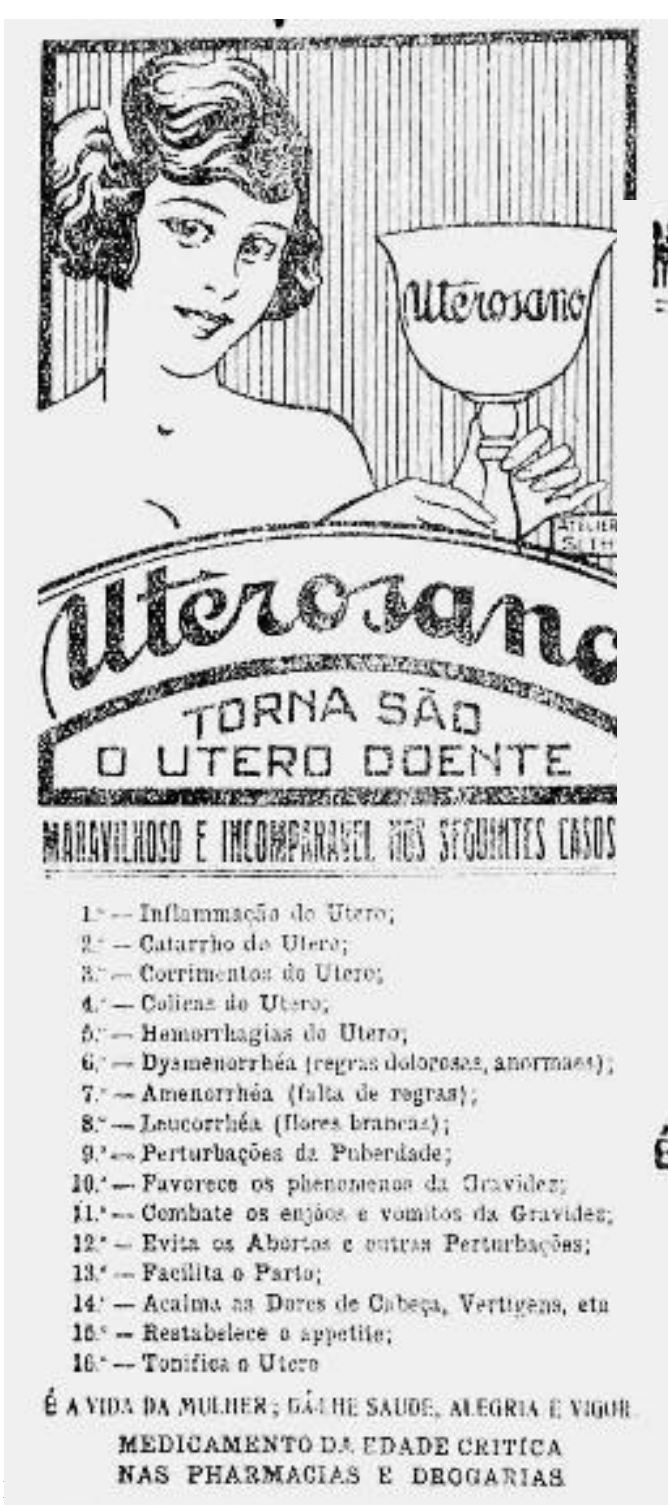

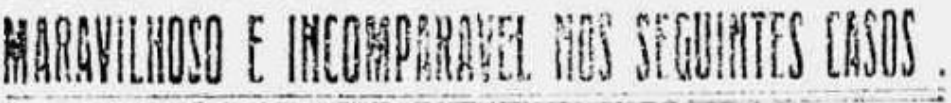

1.- - Inflammação do Utero;

2. - Catarrho do Utero;

3."- - Corrimentos do Utero;

4." - Colicas do Utero;

5." - Hemorrhagias do Utero;

6." - Dysmenorrhéa (regras doloroses, anormaes):

7." - Amenorrhéa (falta de regras);

8." - Leucorrliéa (flores brancas);

9. en Perturbações da Puberdade;

10. - Favorece os phenomenos da Gravidez;

11. - Combate os enjôos e vomitos da Gravidez;

12." - Evita os Abortos e ontras Perturbacoes;

13." - Facilita o Parto;

14: - Acalma as Dores de Cabeça, Vertigens, etc

$15 .^{\circ}$ - Restaivelece o appetite;

16. - Tonifica o Uiero

É A VIDA DA MULHER; DÁLHE SAUDE, ALEGRIA E VIGOR. MEDICAMENTO DA. EDADE CRITICA NAS PHARMACIAS E DROGARIAS.

propagandas, dos anúncios que eram veiculados na cuja argumentação, cuja maneira de entreter seus

consumidore

Figura 3 - Anúncio "Regulador Uterosano", JM, de 16 de outubro de 1930 ' 'm, por afirmações (Figura 3) a respeito da saúde da mulher, pois nesse período, os anúncios e comercialização de medicamentos eram permitidos e livres na imprensa geral. Apenas com 
a Lei da Vigilância Sanitária $n^{\circ}$ 6.360, de setembro de 1976, esses medicamentos viriam a ser anunciados apenas em publicações especializadas.

Nessa mesma propaganda (Figura 3), percebe-se, também, a preocupação com os órgãos reprodutores femininos devido à sua função de procriar. Em um único produto poderia se obter a cura ou controle de diversos problemas que acometiam a saúde das consumidoras (JORNAL DAS MOÇAS, 16 de outubro de 1930, $\mathrm{n}^{\circ} 800$ ).

Muitos dos publicitários que escreviam esses anúncios os faziam de modo familiar, a fim de estreitar relações com a consumidora, de criar uma intimidade, pelo texto, trazendo situações do seu cotidiano tais como: o enaltecimento a beleza, da boa aparência e, especialmente, como fonte para a conquista e a permanência das relações amorosas, da mulher para o homem. Criavam historietas nas quais a consumidora facilmente poderia se identificar. Uma fórmula aparentemente simples, mas o fato desses anunciantes terem perdurado por tanto tempo nas páginas do semanário, indica o sucesso de venda.

Os temas apresentados nas chamadas eram polêmicos. Vendiam felicidade, emanavam ares de seriedade nas afirmações contidas nos anúncios e, conforme a Figura 4, reafirmavam à leitora, numa vertente religiosa, a importância dos fortes laços matrimoniais pelos quais os casais estão ligados, chamando-a à responsabilidade, no sentido de se ter cuidados com sua saúde, aos períodos “a que está exposta todos os mezes”, pois, afinal, ela é a zeladora do lar. 


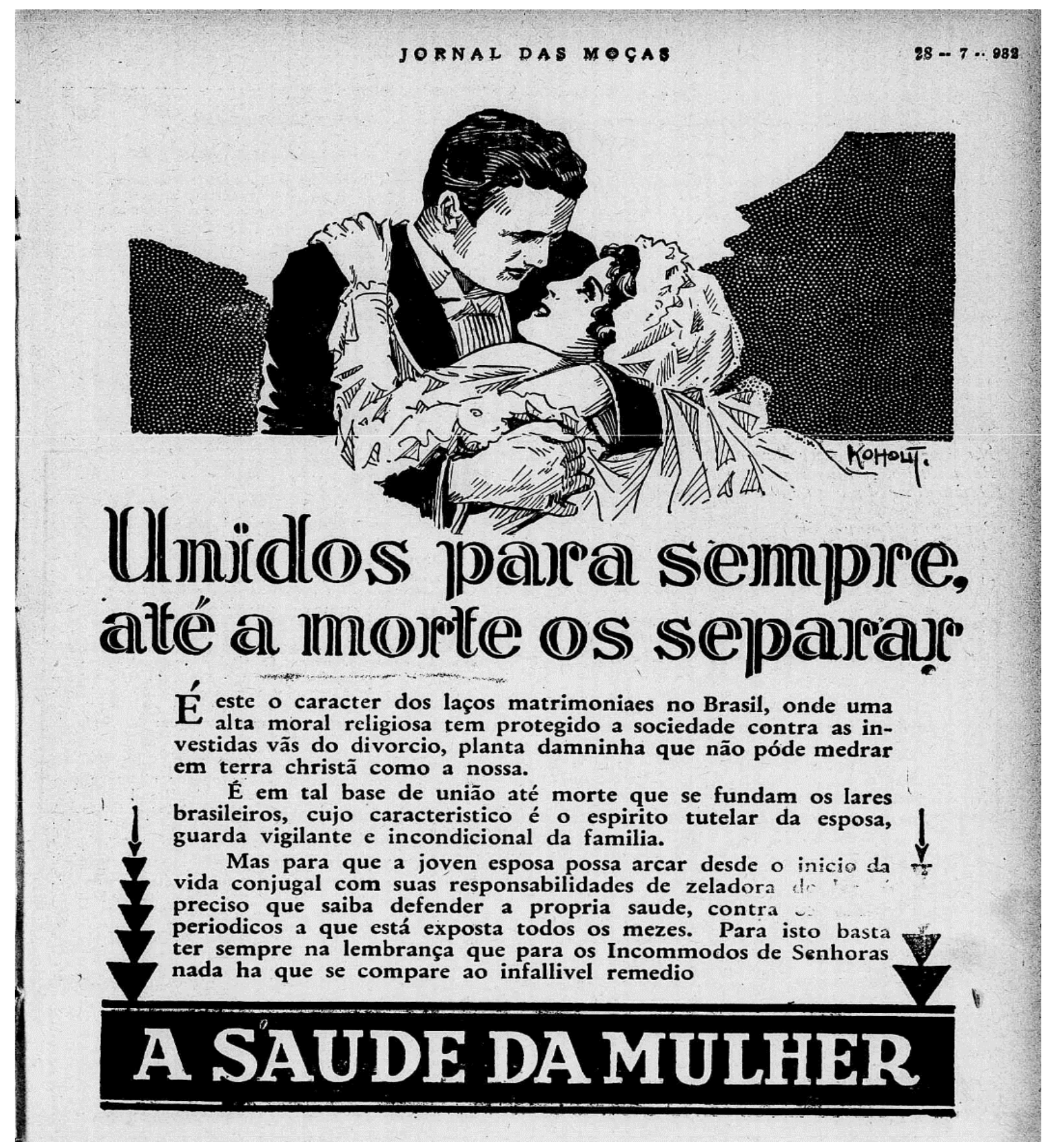

Figura 4 - Anúncio “A saúde da mulher”, JM do ano de 29 de dezembro de 1932

É interessante observar que a intenção do anúncio é a venda do produto. No entanto, também faz referencia ao divórcio ${ }^{8}$, concebido como "erva damninha que não pode medrar em terra christã como a nossa", utilizando-se de uma linguagem moralista e religiosa, delegando à mulher a responsabilidade de manter o casamento, sendo "guarda vigilante $\mathrm{e}$ incondicional da família".

${ }^{8}$ O divórcio só viria a ser instituído no Brasil, em 1977, por meio de da Emenda Constitucional n ${ }^{\circ} 9$ e após sua regulamentação foi transformada na Lei n 6515 , de 1977. 
Percebe-se que as propagandas veiculavam mais do que um produto a ser adquirido, mas, direta ou indiretamente, apresentavam modelos a serem seguidos, prescrições a serem literalmente tomadas. São as muitas representações dos autores, baseadas nas muitas características para homens e mulheres e que produziam diferentes apropriações por suas leitoras.

Para Chartier (2001), "reconhecer como um trabalho tipográfico inscreve no impresso a leitura que o editor-livreiro supõe para o seu público é, de fato, reencontrar a inspiração da estética da recepção, mas deslocando e aumentando seu objeto" (Chartier, 2001, p. 99). Pensar o objeto cultural e, para este texto uma revista feminina impressa, como um espaço construído não apenas constituinte de textos, palavras, mas constituidor de elementos inseridos e de responsabilidade de quem edita, de quem desenha ou ilustra suas páginas, de um impressor. Ampliando horizontes e apresentando significados no intuito de prescrever condutas às leitoras.

Aqui, entende-se que as propagandas compactuavam ideiais políticos, comportamentos, posturas veiculando modelos de corpos, representações de mulheres no lar, de mulheres santificadas, como aparato pedagógico para a educação feminina e esses textos e o seu discurso disseminava e todo o caráter seletivo, eugênico da força física brasileira que o governo Varguista pretendia.

As propagandas inseridas no Jornal das Moças, tanto dos produtos comercializados, dos ornamentos gráficos, das fotografias, quanto na indumentária oferecida nos moldes de costura ou apresentadas pelos artistas hollywoodianos, se configuravam em instrumentos de disseminação de normas para a manutenção da família, da santidade da ordem familiar, da ordem social e também se voltavam para a formação de um modelo de mulher ideal e aceitável. É importante perceber que ao longo de toda a revista, as representações de mulher ideal eram inculcadas em suas leitoras. As frases de efeito, as cartas, as poesias, as propagandas, em tudo era facilmente possível detectar por qual caminho a mulher deveria andar. A mulher forte, íntegra e sadia para criar seus filhos; os filhos da nação brasileira.

\section{AS REPRESENTAÇÕES DE RURALIDADE NOS GUIAS DE APRENDIZAGEM DA ESCUELA NUEVA COLOMBIANA}

A leitura como atividade criadora e o livro como campo instaurador de ordens de interpretação configuram-se nos dois elementos fundamentais para entender o papel da 
utilização dos protocolos de leitura como quadro metodológico na pesquisa sobre livros didáticos. Para o presente texto os livros didáticos foram, precisamente, sua fonte privilegiada, objetivando compreender as representações da ruralidade inscritas nas Guias de Aprendizagem do modelo Escuela Nueva na Colômbia.

A Escuela Nueva é criada em um período em que o campo, enquanto objeto de educação, estava sendo pensado e discutido na América-Latina, devido à necessidade de investimentos e propostas educacionais que atendessem suas características e necessidades. Nesse momento, a Escuela Nueva se projetava como uma alternativa viável que atendia as particularidades da escola rural enquanto instituição escolar multisseriada, que funcionava com um único professor para as diferentes series, com estudantes em idades e aprendizagens heterogêneas que desenvolvem tarefas agrícolas com as famílias. A principal ferramenta utilizada por essa modalidade escolar para responder às particularidades da escola no campo denominou-se como Guias de Aprendizagem, elaborados para a $2^{\circ}$ série até a $5^{\circ}$ série; tratadas, nesta pesquisa, como manuais escolares para a ruralidade.

Através dos manuais escolares são construídas pontes entre a cultura, a sociedade e a escola. Eles se convertem nos mensageiros das percepções de mundo e intenções de formação para as novas gerações. Porém, sua análise deve ser realizada com cautela pois, como produtos culturais que são, estão carregados de intenções, não são neutros, possuem representações sobre os saberes a serem apreendidos e estratégias para impor tais representações. Sua complexidade se encontra nas múltiplas funções que cumprem, as quais, como afirma Choppin (2002, p. 13), em sua maioria passam "totalmente despercebidas aos olhos contemporâneos". É possível que isso se deva à familiaridade com a que os sujeitos têm se relacionado com ele. É um objeto que possui presença permanente na escola e uma ampla difusão.

Para a História da Educação, o manual configurou-se, durante as últimas décadas do século passado, como uma fonte privilegiada para a pesquisa na escola, enquanto ferramenta que contém muito mais que conteúdo educativo explícito; cumprindo o papel de transmitir às jovens gerações os saberes e comportamentos que uma determinada sociedade considera indispensáveis para se perpetuar, pois este:

[...] veicula, de maneira mais ou menos sutil, mais ou menos implícita, um sistema de valores morais, religiosos políticos, uma ideologia que conduz ao grupo social de que ele é a emanação: participa, assim, estreitamente do processo de socialização, de aculturação (até mesmo de doutrinamento) da juventude (CHOPPIN, 2002, p. 14). 
Nesse sentido, pensar as Guias enquanto manuais escolares, como fontes para a pesquisa, implica compreendê-las como um objeto para se ler e um instrumento para se utilizar, pois, como característica particular, entende-se que eles estão pensados para a prática, para "fazer-fazer” ao leitor. No Programa Escuela Nueva, as Guias de Aprendizagem se configuram em uma das ferramentas centrais, o que tem levado a escola, na utilização dessa metodologia, a se denominar como "a escola instrumental" (PARRA, 1996). Como sinaliza Parra (1996, p. 20-21), as Guias são os elementos dominantes, "ao redor desse elemento se organizam e adquirem sentido os outros elementos [...] não é uma ajuda para desenvolver o currículo, ela é o currículo mesmo (no sentido restrito) e um super professor [...] é o centro do mundo escolar".

Como se pode notar, entender Escuela Nueva implica pensar em seu elemento preponderante, aquele que, como sinaliza o autor, se configura no eixo central ao redor do qual os outros elementos gravitam: as Guias de Aprendizagem. Estas não se caracterizam como um auxílio do professor, pois nesse modelo escolar, voltado para uma aprendizagem autônoma, o professor não é protagonista do processo, por isso ele, para sua atuação, precisa também ser instrumentalizado pelo material.

Devido à importância das Guias na Escuela Nueva, elas se converteram em fontes para a compreensão das representações veiculadas no Programa. Foram tomados, então, para análise as Guias de Aprendizagem da área de Ciências Sociais, da 2 à 5 a séries, constituindo um corpus de 11 textos. Esse material foi editado e impresso no final do ano 1987 e reimpresso no ano 1989, momento em que esse modelo já estava consolidado na Colômbia, por isso o período analisado perfaz o recorte temporal de 1970 a 1990.

A análise desses manuais escolares, por meio dos protocolos de leitura, teve como foco os conteúdos que tratam sobre o rural, as leituras sugeridas para o camponês, o nível de complexidade do conteúdo, os questionários e exercícios antes e depois da leitura, as frases que operam como sentenças moralizantes, as imagens que representam formas culturais e sociais válidas sobre determinadas instituições, ações e sujeitos e, sobretudo, a forma na qual se estrutura o texto.

Levando-se em conta os pressupostos teóricos sobre os protocolos de leitura, realizouse a análise tendo como categorias de análise: o espaço e a paisagem, a escola, o camponês, a comunidade, o Estado, as normas e autoridade, e a relação campo- cidade.

A forma principal na qual se apresentam as informações no manual escolar para a ruralidade da Escuela Nueva pode ser denominada de narrativa didática. Diversas situações 
cotidianas são contadas, como estórias que indicam uma forma "adequada" de pensar e sentir frente às diversas situações, do cotidiano camponês. Frases simples, parágrafos curtos e histórias lineares estruturam o texto. Utilizam-se exercícios prévios (perguntas ou atividades dirigidas sobre o tema a tratar) e logo se convida à leitura grupal, à discussão sobre ela e a responder uma série de questões direcionadas.

Os conteúdos estão estruturados numa espiral, que se volta permanentemente sobre um tema, propondo novos cenários para reforçar o aprendido. Por exemplo: nas primeiras séries utiliza-se o entorno próximo e este se vai ampliando a perspectiva até chegar às últimas séries, onde se pensa o país. Mas, a forma de transformação do lugar, qualquer que ele seja, é só pelo trabalho. Esse movimento circular, que busca partir de lugares comuns, de discursos já utilizados e abordados nas séries anteriores para legitimar uma ideia ou um conteúdo é evidentemente uma forma garantir sua apropriação. Esta característica é, sem dúvida, o aspecto mais representativo em termos de protocolos de leituras, pois se refere ao fato de pensar cada uma das histórias, das perguntas, das imagens partindo do contexto rural, para depois trabalhar temáticas da história e da geografia nacional.

Os protocolos excedem o conteúdo textual; eles se apresentam nas formas, cores, tamanhos, diretrizes de leituras adequadas e, no caso das Guias de Aprendizagem, se apresentam como criadores de rotinas de leitura e de trabalho com as mesmas. A análise focalizou, também, as regulações do ato de ler, quer dizer, não só do lido enquanto conteúdo, mas também da forma autorizada para lê-lo e para realizar as tarefas solicitadas.

O processo de leitura para diferentes vozes, mas, entre os estudantes parece ser a prática de leitura mais solicitada. Como afirmara Rockwell (2001), a leitura nas salas de aula é uma atividade social, tem intercâmbio de vozes, entonações, ritmos e ideias que configuram interpretações diversas. A prática da leitura em voz alta, ao redor de uma mesa, em disposição para trabalhar a partir do texto, configura uma forma de sociabilidade escolar particular, que mesmo não sendo exclusiva da Escuela Nueva, pode-se afirmar que é predominante nesse modelo.

Todas as características anteriormente descritas podem ser concebidas como parte dos protocolos de leitura que se inscrevem no texto para determinar a leitura autorizada. $\mathrm{Na}$ prática, as maneiras de ler criam fissuras por onde se estruturam sentidos e significados diversos do lido.

As categorias de análise salientadas anteriormente (espaço e paisagem, a escola, o camponês, a comunidade, o Estado, as normas e autoridades, e a relação campo-cidade) 
permitiram realizar uma leitura detalhada dos aspectos que, nos textos, evidenciam as representações sobre o rural veiculadas de maneiras diretas e sutis.

As buscas por estruturar uma forma de ser camponês, sujeito que trabalha no campo e que constrói sua identidade cultural nesse meio, de habitar o espaço rural e de se relacionar com as instituições sociais (Escola, Estado) e mesmo com a cidade estão presentes no texto a partir de imagens, estórias ou instruções.

O conceito de camponês foi socialmente construído. Percebe-se a partir da leitura das Guias que o ser camponês envolve práticas inerentes à condição que lhe são peculiares, pois, uma vez que se nasce camponês e se mantém como tal, o sujeito se circunscreve a uma maneira particular de habitar o mundo, na qual o trabalho agropecuário é uma das marcas mais importante, já que a relação com o espaço se tece por meio da produtividade da terra, fortalecendo as relações comunitárias e as tradições culturais (formas particulares de vestir, comida, festas, crenças).

Em cada uma das séries, várias unidades abordam o tema do trabalho agropecuário e sua conexão com o desenvolvimento do país. Porém, essa representação não só se constrói por meio dos conteúdos explícitos mas, também, dos implícitos, uma vez que o pano de fundo de todas as temáticas é a relação do camponês com o espaço. Assim, o ser camponês tem uma vinculação com o ser cidadão, de uma maneira diferente daquela que estabelece o sujeito urbano pois, no campo, a comunidade cumpre um papel fundamental de representação e organização coletiva, que termina por cumprir o papel do Estado.

A comunidade também se configura como um dos elementos mais importantes na constituição da ruralidade pois, nela são estabelecidas relações de cooperativismo entre os sujeitos, aproveitando o entorno, transformando-o e produzindo. É concebida como uma força trabalhadora que supre as várias funções estatais. Constrói estradas, melhora os espaços coletivos, estabelece os serviços públicos, elege seus representantes e, como um fato significativo, estabelece uma relação de apoio permanente à escola, da parte de infraestrutura (pois se lhe reclama a colaboração permanentemente para a melhoria do espaço da escola e da sua dotação), até a participação constante no processo educativo. As representações de uma comunidade sempre disposta são latentes nas Guias, como se pode perceber na narrativa a seguir:

Una buena campaña

Don Serafín se encontró con don Angélico y le comentó que un niño de Escuela Nueva le había entregado una carta que decía: "Estimado señor: El camino que va a la escuela está muy malo. ¿No podríamos arreglarlo entre todos?" A don Angélico le gustó mucho que los niños de Escuela Nueva 
estuvieran haciendo esa campaña. Así que acordó con don Serafín reunirse con todos los hombres de la vereda con el fin de arreglarlo. Todos los hombres de la vereda se reunieron y arreglaron el camino. Los niños de Escuela Nueva también ayudaron. La profesora de la escuela dio las gracias por la campaña que hicieron. Después, los niños organizaron otra campaña para arreglar el patio y el techo de la escuela. (GUIA DE CIENCIAS SOCIALES, SERIE 2, UNIDAD 5, OBJETIVO 3, p. 35).

Nessas linhas, as crianças são conclamadas a cobrar da comunidade a devida colaboração. A precariedade e o abandono estatal não geram, segundo as Guias, protesto ou manifestação; pelo contrário, geram atitudes de solidariedade coletiva.

Analisando as representações de Estado, o material didático pretende mostrar em suas páginas a atuação deste enquanto poder público, através das instituições constituídas para o apoio à produção agrícola. Demonstra não ter um projeto de apoio integral ao desenvolvimento rural, expressando o interesse somente em relação ao crescimento econômico, missão encarregada ao camponês.

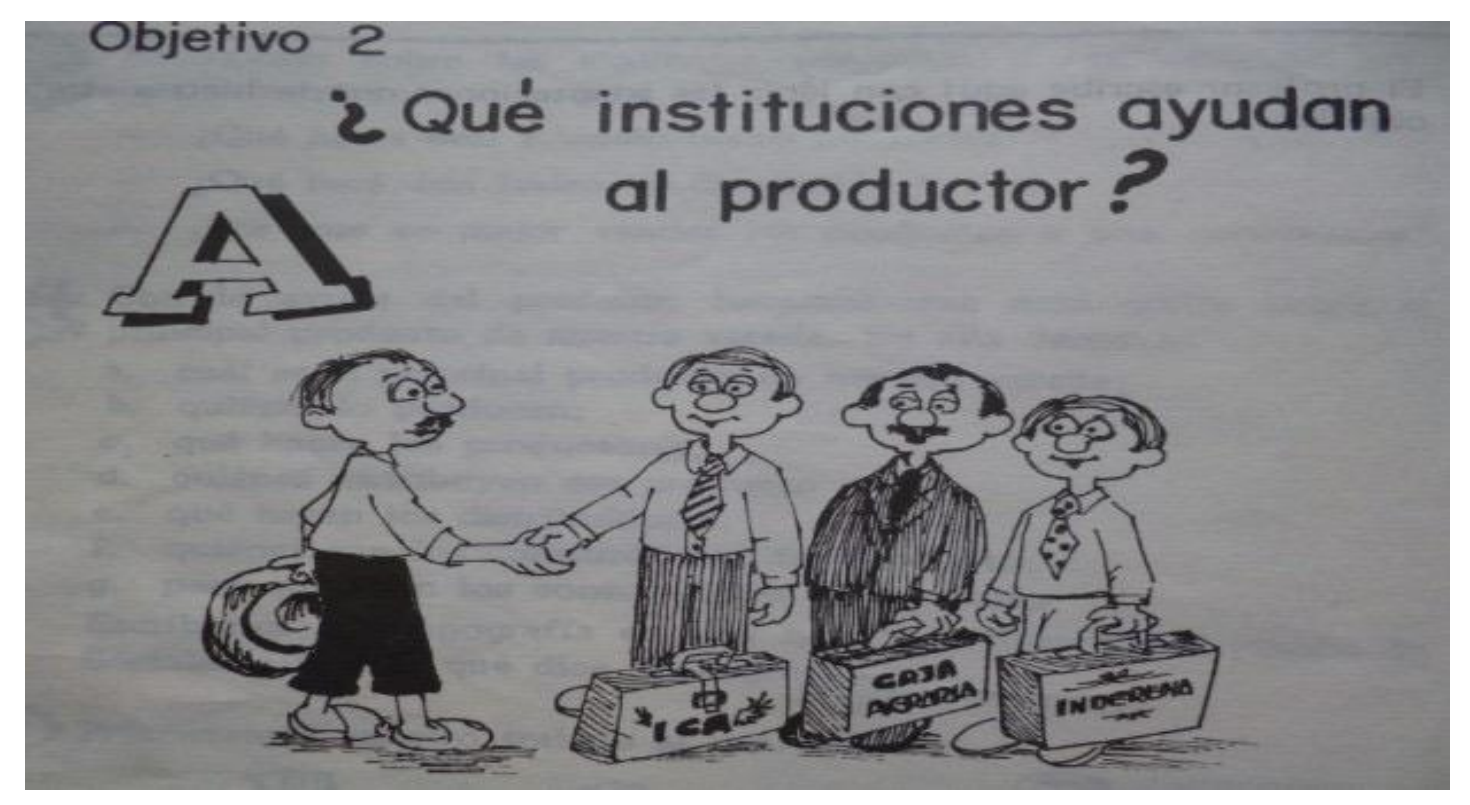

Figura 5 Guia de Ciências Sociais, Série 3, Unidade 6, Objetivo 2, p. 46 Fonte: Acervo Instituição Educativa Escuela Normal Superior de María, Rionegro- Antioquia, Colômbia.

Nota-se que, quando o Estado o reconhece como produtor, o camponês obtém visibilidade no cenário nacional, por cumprir seu papel na economia. Essas instituições não tiveram uma abrangência nacional, pois o apoio era para quem podia produzir. A visão nomeadamente econômica se revela novamente na metodologia da Escuela Nueva. Na figura 5, se apresentam o Instituto Colombiano Agropecuário - ICA; a Caixa Agrária e o Instituto Nacional Agropecuário -INDERENA. 
Voltando a análise para a relação campo-cidade, três representações são visíveis nas Guias de Aprendizagem: a primeira refere-se à relação simbiótica, na qual os cenários interagem a partir da diferença, sem estabelecer desigualdade ou relações de poder de um cenário sobre o outro; a segunda, apresenta uma dicotomia entre campo e cidade, colocando o primeiro como um lugar idílico, tranquilo, de relações interpessoais harmônicas e de trabalho para todos, sendo que a cidade é apresentada como um lugar de poucas oportunidades e excludente para o camponês; e a terceira representação coloca a cidade como um lugar com mais condições materiais, sem que isso signifique um ponto negativo para o campo, pois este pode transformar sua realidade com a participação comunitária. De acordo com Alzate, Gómez y Romero (1999, p. 65) em tais ideais "la ambición social no está en la enunciación de las virtudes" visa-manter um tipo de estabilidade social.

Procura-se a ajuda da cidade para receber serviços médicos, para comprar produtos industrializados como roupas, sapatos, ferramentas escolares ou produtos para o cultivo, como inseticida. Dirige-se à cidade para vender os produtos de cultivo, mas sempre se regressa, como no texto a seguir:

\footnotetext{
La visita al pueblo

Juan llegó al pueblo con su papá y su mamá. Fueron a la plaza de mercado y vendieron los productos que llevaban. Después hicieron compras. A Juan le compraron unos zapatos negros y un sombre (...) se encontraron con varios miembros de la acción comunal de la vereda. Ellos estaban comprando unas tejas para la escuela. Todos juntos regresaron por la tarde a la vereda. (GUÍA DE CIENCIAS SOCIALES, SÉRIE 2, UNIDAD 4, OBJETIVO 3, p. 17-18).
}

A história narrada a seguir apresenta com clareza quais eram as mensagens que circulavam pelo livro, evidenciando a necessidade de reivindicar o campo como um lugar privilegiado para se viver, contrapondo a ideia que colocava a cidade como um lugar melhor:

El viaje de la familia cadena

La familia Cadena era muy apreciada en la vereda caño blanco. Todo mundo decía que eran muy trabajadores, que no hablaban mal de los demás y que eran muy serviciales. Pero un día corrió el rumor de que el señor Cadena y su familia se iban para la ciudad. Varios vecinos fueron a ver si la noticia era cierta. -Sí - decía Luis Cadena-. Me voy. Ya casi arreglo la venta de la parcela. -Pero... ¿Por qué se va, don Luis? -Preguntaba la señorita Anita. -Por muchos motivos -respondió don Luis-. En primer lugar, porque la parcela ya no me da para vivir. Además, ustedes recuerdan que hace pocos 
días mi niño menor estuvo muy enfermo durante mucho tiempo por falta de un médico que lo viera, y además. Adelita ya está terminando su primaria y deseo matricularla en un colegio de bachillerato en el pueblo. También me parece que el agua en esta vereda no es muy buena. -Pues yo le digo una cosa -dijo don Rafael-. El más viejo de la vereda, usted, tiene muy buenas razones para irse a la ciudad. Y yo no le digo que no se vaya, pero sí le pido que piense muy bien lo que va a hacer para que no le salga todo peor. -¿Cómo así, don Rafael? -Pues fíjese bien -continuó don Rafael-. Yo he visto mucha gente que se va para la ciudad buscando el paraíso. ¿y qué encuentran allá? En primer lugar, desempleo: no consiguen trabajo por ninguna parte. En segundo lugar, hambre, pues si no hay trabajo no hay que comer, y como ya no tienen la parcelita para coger aunque sea la yuca. Hay que apretarse al cinturón. En tercer lugar, se les acaba la familia, pues tienen que aceptar que sus hijos se coloquen en cualquier arte para poder sobrevivir. -Y no sólo eso -interpeló doña Anita-. La corrupción... a lo mejor sus hijos se van por el mal camino y ahí sí que se termina todo... -Exactamente -confirmó don Rafael-. Y usted dice que se va para que Adelita estudie bachillerato. Pero si usted no consigue trabajo, no habrá bachillerato para ella y entonces le tocará rebuscarse la vida de cualquier manera y quedarse así, medio ignorante. -Sí -dijo don Misael-. En lugar de irse, Luis, lo que tenemos que hacer es ayudarnos para que los problemas que usted ha tenido no los vuelva a tener otra persona. Ayudemos todos a organizarnos para tener un puesto de salud en la vereda. Ayudemos todos a organizarnos para tener un puesto de salud en la vereda. Ayudemos a construir un acueducto que nos dé agua pura. Reunamos todos los niños que acabaron la primaria, construyamos un salón y pidamos un profesor que les ayude a hacer el bachillerato por radio... Sí, hombre Luis -dijo don Rafael-. Ayúdenos a arreglar esto. Don Luis Cadena se levantó de su asiento y mirando a todos sus amigos les habló: -Yo pienso que el puesto de salud queda bien en la planada de don Misael. Y pienso que debemos organizar una buena cooperativa para vender mejor nuestros productos en el pueblo. -¡Bravo! ¡Bravo! -dijeron los amigos de la familia Cadena-. ¡Ya no se van! Todos abrazaron a don Luis, llenos de alegría. La esposa de don Luis que había oído todo, lloraba de emoción. (GUIA DE CIENCIAS SOCIALES, SERIE 4, UNIDAD 4, OBJETIVO 2, p. 65-67).

Ainda que sejam inúmeros os discursos, tanto textuais como imagéticos, sobre as representações campo-cidade, a narração permite observar vários aspectos. Em primeiro lugar, apesar de ter um reconhecimento das problemáticas camponesas (falta de saúde, educação secundária e problemáticas econômicas) elas eram inferiores às problemáticas da cidade, apresentada como um lugar hostil ao camponês. Nessa medida, a comunidade deve se unir, evitando migração de outros camponeses, solucionando as diversas carências.

A ordem, o progresso, a cooperação, o trabalho agrícola industrializado, a presença do Estado e a ausência do conflito superior aos cotidianos, configuram um campo pensado e dado a ler através das guias de aprendizagem. São estas as representações sobre o rural que as Guias de Aprendizagem apresentam de maneiras diversas procurando instaurar uma forma particular de se compreender o campo e de agir diante dele. 


\section{CONSIDERAÇÕES FINAIS}

A utilização dos protocolos de leitura como ferramentas metodológicas da História da Leitura trazidas para o estudo de dispositivos escritos no campo da educação, constrói pontes para a escrita da História da Educação, ampliando a perspectiva não só sobre a utilização de diversas fontes, mas também sobre diferentes perguntas e metodologias neste campo. Ferramentas que devem garantir rigorosidade da pesquisa, mas também novos olhares, novas direções e novas formas de mergulhar nos dispositivos escritos.

Através da análise da revista Jornal das Moças, percebe-se as representações do “ideal" de mulher presentes nos artigos, anúncios, ilustrações e matérias. Os protocolos de leitura auxiliaram esta investigação para compreender a revista em sua materialidade e como veículo discursivo e formador de um projeto educativo para a formação de mulheres, dentro do recorte temporal escolhido, descortinando sua lineraridade ao manter princípios de formação de mulheres para o lar, para educar seus filhos, para a formação desse exército no estabelecimento da ordem social, desde o seu lançamento até o seu último número que esteve em circulação e levando a leitora a ler da forma como seus textos eram pensados e produzidos.

Observou-se, especialmente, que os protocolos de leitura como instrumento metodológico auxiliam o pesquisador a voltar o seu olhar para a fonte e extrair resultados nas minúcias impregnadas nos aspectos materiais de um impresso, como o tipo de papel usado, as cores, os espaços escolhidos para disposição das fotos, imagens, textos e propagandas veiculadas, associadas na mente do autor e do editor, a partir de um leitormodelo em que, também a revista evocava um jogo identitário entre a leitora, o autor e seu discurso estabelecido.

Já nas Guias de Aprendizagem das Escuelas Nuevas, essa metodologia possibilitounos perceber que a ideia de rural, recorrente nos textos, é precisamente a representação de um campo harmonioso, pacífico, com presença permanente do Estado, produtivo e que não altera as tradicionais formas de diferenciação social. Esse campo, que não é um reflexo direto da sociedade, mas sim uma representação de como deveria ser o campo, demonstra a busca por manter o discurso de um cenário "natural" para o camponês, ao qual pertence. Busca evidente nos textos analisados através dos protocolos de leitura. 
Nesse sentido, a busca pelo registro dos leitores é ação importante ao se investigar um impresso, uma revista, um manual escolar, uma guia de aprendizagem. Por meio deles é possível se extrair elementos na tentativa de compreender a visão que o leitor tem do texto, o quanto ele diverge das ideias postas pelo autor, o quanto ele as incorpora, por meio dos dispositivos criados na concepção pós-moderna de autor. No marco da História da Leitura, utilizam-se os protocolos de leitura como os dispositivos de inteligibilidade da leitura autorizada pelo texto, as maneiras de ler pelo leitor, que partem do encontro entre o mundo do texto e o mundo do leitor.

Assim, no campo da História da Educação, sua abrangência, sua pluralidade de objetos, fontes e associação de métodos de investigação é que se reflete sobre a educação como um fenômeno social que transcende a relação consigo e com o outro, através do tempo e do espaço. Portanto, não se pode pensa-la e restringi-la a uma instituição escolar, de um espaço formal. Sem deixar de reconhecer o papel fundamental que como instituição social cumpre a escola. Problematizou-se aqui as possibilidades de se contribuir com a História da Educação, a partir do projeto de formação que a revista Jornal das Moças se configurava e das guias de aprendizagem da Escuela Nueva para demonstrar como o campo da História da Educação transcende as fronteiras escolares e pode ampliar seu olhar através de diversos objetos e utilizando diferentes fontes, através dos protocolos de leitura.

\section{REFERÊNCIAS}

ALZATE, M.; GÓMEZ, M.; ROMERO, F. Textos escolares y representaciones sociales de la familia 1. Definiciones, dimensiones y campos de investigación. Bogotá: Editorial Cargraphics. Colciencias-Universidad Tecnológica de Pereira, 1999, 104 p.

BRASIL. Lei $n^{\circ}$ 6.515, de 26 de dezembro de 1977. Regula os casos de dissolução da sociedade conjugal e do casamento, seus efeitos e respectivos processos. Disponível em: http://www.planalto.gov.br/ccivil_03/leis/16515.htm Acesso em: 15 Mar.2017

CHARTIER, R. Do livro à leitura. In: CHARTIER, R. (Org.). Práticas de Leitura. Tradução de Cristiane Nascimento. São Paulo: Estação Liberdade, 2001, p. 229-253.

CHARTIER, R. O mundo como representação. In: CHARTIER, R. A beira da falésia: a história: entre certezas e inquietude. Porto Alegre: Ed. UFRGS, 2002

A história cultural: entre práticas e representações. Lisboa: Difel; São Paulo:

Betrand Brasil, 1990. 
LUCA, T. R. de. Mulher em revista. In: PINSKY, C. B.; PEDRO, J. M. (Org.). Nova História das Mulheres no Brasil. São Paulo: Contexto, 2012. 555 p.

PARRA, R. A Escuela Nueva. Bogotá: Plaza \& Janes. 1996. 351 p.

PINSKY, C. B. A era dos modelos rígidos. In: PINSKY, C. B.; PEDRO, J. M. (Org.). Nova História das Mulheres no Brasil. São Paulo: Contexto, 2012. p. 555.

ROCKWELL, E. La lectura como práctica cultural: conceptos para el estudio de los libros escolares. Educação e Pesquisa, São Paulo, v. 27, n. 1, p, 11-26. 2001.

SCHWARTZMAN, S.; BOMENY, H. M. B.; COSTA, V. M. R. Tempos de Capanema. Rio de Janeiro: Paz e Terra; São Paulo: Editora da Universidade de São Paulo, 1984.

\section{FONTES DOCUMENTAIS CITADAS}

COLBERT, V.; MOGOLlÓN, O. "Hacia una Escuela Nueva. Unidades de capacitación para el maestro”. 3. ed. Ministerio de Educación Nacional, Colombia, 1987. 275 p.

JÉREZ E.; COLBERT, V. Guia de aprendizagem de Ciências Sociais. 2. ed. $2^{\text {a }}$ Série, Unidades 1-8. 1987, 1989.

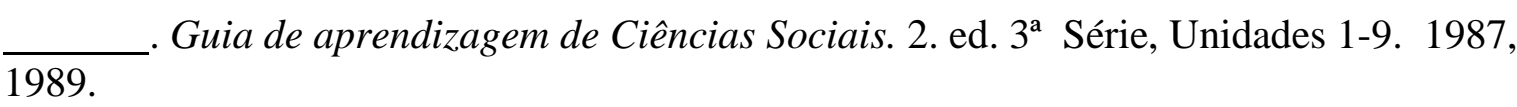
1989.

. Guia de aprendizagem de Ciências Sociais. 2. ed. 4ª Série, Unidades 1-9. 1987,

BRASIL. Jornal das Moças. Ano 1, Número 01. Rio de Janeiro, 21 de maio de 1914. Edição disponível para consulta na Hemeroteca Digital da Biblioteca Nacional.

BRASIL. Jornal das Moças. Ano 1, Número 02. Rio de Janeiro, 1 de junho de 1914. Edição disponível para consulta na Hemeroteca Digital da Biblioteca Nacional.

BRASIL. Jornal das Moças. Ano 3, Número 44. Rio de Janeiro, 1 de março de 1916. Edição disponível para consulta na Hemeroteca Digital da Biblioteca Nacional.

BRASIL. Jornal das Moças. Ano 17, Número 800. Rio de Janeiro, 16 de outubro de 1930. Edição disponível para consulta na Hemeroteca Digital da Biblioteca Nacional.

BRASIL. Jornal das Moças. Ano 19, Número 915. Rio de Janeiro, 29 de dezembro de 1932. Edição disponível para consulta na Hemeroteca Digital da Biblioteca Nacional.

BRASIL. Jornal das Moças. Ano 27, Número 1285. Rio de Janeiro, 1 de fevereiro de 1940. Edição disponível para consulta na Hemeroteca Digital da Biblioteca Nacional.

BRASIL. Jornal das Moças. Ano 27, Número 1294. Rio de Janeiro, 4 de abril de 1940. Edição disponível para consulta na Hemeroteca Digital da Biblioteca Nacional. 
VIVAS, Y. Guia de aprendizagem de Ciências Sociais. 2. ed. $5^{\text {a }}$ Série, Unidades 1-9. 1987.

Data de recebimento: $17 / 07 / 2017$

Data de aceite: 29/09/2017 